\title{
Does the Segregation of Evolution in Biology Textbooks and Introductory Courses Reinforce Students' Faulty Mental Models of Biology and Evolution?
}

\author{
Ross H. Nehm • Therese M. Poole • Mark E. Lyford • \\ Sally G. Hoskins • Laura Carruth • Brent E. Ewers • \\ Patricia J. S. Colberg
}

Published online: 19 November 2008

(C) Springer Science + Business Media, LLC 2008

\begin{abstract}
The well-established finding that substantial confusion and misconceptions about evolution and natural selection persist after college instruction suggests that these courses neither foster accurate mental models of evolution's mechanisms nor instill an appreciation of evolution's centrality to an understanding of the living world. Our essay explores the roles that introductory biology courses and textbooks may play in reinforcing undergraduates' preexisting, faulty mental models of the place of evolution in the biological sciences. Our content analyses of the three best-selling introductory biology textbooks for majors revealed the conceptual segregation of evolutionary infor-
\end{abstract}

\section{R. H. Nehm $(\bowtie)$}

College of Education and Human Ecology,

The Ohio State University,

Columbus, OH 43210, USA

e-mail: nehm.1@osu.edu

\section{R. H. Nehm}

Department of Evolution, Ecology, and Organismal Biology,

The Ohio State University,

Columbus, OH 43210, USA

T. M. Poole $\cdot$ L. Carruth

Department of Biology, Georgia State University,

Atlanta, GA 30302, USA

M. E. Lyford · B. E. Ewers

Department of Botany, University of Wyoming,

Laramie, WY 82071, USA

S. G. Hoskins

Department of Biology, The City College,

NY, NY 10031, USA

\section{P. J. S. Colberg}

Department of Zoology and Physiology, University of Wyoming,

Laramie, WY 82071, USA mation. The vast majority of the evolutionary terms and concepts in each book were isolated in sections about evolution and diversity, while remarkably few were employed in other sections of the books. Standardizing the data by number of pages per unit did not alter this pattern. Students may fail to grasp that evolution is the unifying theme of biology because introductory courses and textbooks reinforce such isolation. Two goals are central to resolving this problem: the desegregation of evolution as separate "units" or chapters and the active integration of evolutionary concepts at all levels and across all domains of introductory biology.

Keywords Evolution education · Textbooks · Mental models $\cdot$ Undergraduates

We give a false picture if we teach evolution only in a single chapter of its own. (G. G. Simpson, in Mayfield et al. 1960)

Every topic in biology is related to and dependent on evolutionary analyses, and so every chapter of an introductory biology book should make these connections and applications clear. (Hillis 2007)

\section{Introduction}

Introductory biology is one of the most highly enrolled science courses in the United States (Woodin 2005) and therefore provides biology educators with a unique opportunity for presenting majors, non-majors, and future teachers with the evidence for evolution and its explanatory power in the life sciences (Kennedy 2005). The fact that 
substantial confusion and misconceptions about evolution persist after instruction suggests that these courses neither foster accurate mental models of evolution's mechanisms nor instill an appreciation of evolution's centrality to an understanding of the living world (Miller et al. 2006; Nehm and Reilly 2007; Nehm and Schonfeld 2008). >Indeed, despite the fact that most biology teachers and medical professionals have demonstrated competency in biology content, they continue to harbor major misconceptions and antievolutionary attitudes (Brumby 1984; Bishop and Anderson 1990; Greene 1990; Settlage 1994; Clough and Wood-Robinson 1985; Demastes-Southerland et al. 1995; Chinsamy and Plaganyi 2007; Nehm and Schonfeld 2007). We explore the question of whether introductory biology courses - and the textbooks they use-are reinforcing rather than restructuring undergraduates' pre-existing mental models of biology and evolution.

Mental models have long served as an important concept in education in general and biology education in particular (Gentner and Stevens 1983; Anderson and Demitrius 1993; d'Apollonia et al. 2002). Although definitions of mental models have varied greatly depending on the context of their use (Johnson-Laird 1983), most tend to encompass internal representations of knowledge that are structured as cognitive maps, schemas, or frameworks (Johnson-Laird 1983). These internal representations are thought to guide cognitive tasks by serving as facilitators (or inhibitors) of knowledge retrieval, problem solving, and conceptual understanding (d'Apollonia et al. 2002). Although several studies have explored in detail student mental models of particular biological phenomena within ecology and evolution (e.g., Anderson and Demitrius 1993; d'Apollonia et al. 2002; Anderson et al. 2001), no research to our knowledge has explored biology students' cognitive maps, schemas, or mental models of biology as a whole. It is important to understand the structure of students' internal representations of biology knowledge in order to explore how these cognitive frameworks facilitate or inhibit thinking about biological concepts such as evolution.

Biology educators need to identify the types of mental models, accurate or inaccurate, that students harbor prior to instruction and need to study how these models are affected by introductory biology coursework (cf. Nehm and Reilly 2007; Handelsman et al. 2004). Figure 1 explores a small subset of the universe of possible cognitive frameworks of biology that undergraduates are likely to harbor of the major subjects covered in introductory biology courses and textbooks. The first mental model (Fig. 1a) represents cognitive organization around isolated content areas. Such a mental model (1) lacks a conceptual organizer linking overall biological knowledge, (2) lacks integration among the individual content domains, and (3) lacks inclusion of evolution as a necessary or important content domain within biology. A second mental model (Fig. 1b) represents a more desirable, but nevertheless unsatisfactory, map of biological understanding. In this cognitive model, the integration among most content domains has been achieved (e.g., conceptual networks are well integrated among genetics and cell biology), but the mental model remains in need of an overarching conceptual organizer and is in need of the integration of evolution into the framework. A third mental model (Fig. 1c) is one that we consider to be more accurate but likely lacking in most biology undergraduates. Overall, our concern is that introductory biology courses and textbooks, as currently structured, may reinforce pre-existing, unsatisfactory mental models of biology.

\section{Biology Textbooks, Curricula, and Mental Models}

Despite the fact that most biologists consider evolution to be a unifying concept of their discipline (Huxley 1960; Dobzhansky 1973), many introductory biology courses do not employ evolution as a cognitive framework for organizing cell biology, genetics, developmental biology, animal biology, plant biology, and ecology. Frequently, faculty syllabi correspond to the curricular structures of biology textbooks (Mayfield et al. 1960). In textbooks and in classrooms, "ecology," "mechanisms of heredity," and "biochemistry of life" are presented as separate units; evolution is likewise compartmentalized into a single chapter or set of related lectures. Does this structure reinforce the idea that "nothing in biology makes sense except in the light of evolution?" Or, rather, does it reinforce mental models that evolution has little to do with the rest of biology (Fig. 1a)?

We are interested in how introductory biology textbooks for majors structure and distribute evolutionary information and what implications this structure may have for learning evolution. Textbook analyses, technically known as Content Analysis (e.g., Krippendorff 2004), have long served an important role in biology education by providing a methodology for gathering data on how disciplinary knowledge has been structured through time (Skoog 1979) and across different countries (Swarts et al. 1994). In order to determine which textbooks are most often used by faculty today, we asked multiple publishers at several national conferences what they considered to be the bestselling introductory biology textbooks for majors, as no publicly accessible data are available for answering this question empirically. Three textbooks were consistently mentioned by all publishers as the top sellers: Campbell and Reece (2004), Purves et al. (2003), and Freeman (2004). We thus chose to perform a content analysis on these three texts.

Previous textbook analyses of evolutionary content guided our study (Hellman 1965; Swarts et al. 1994). 


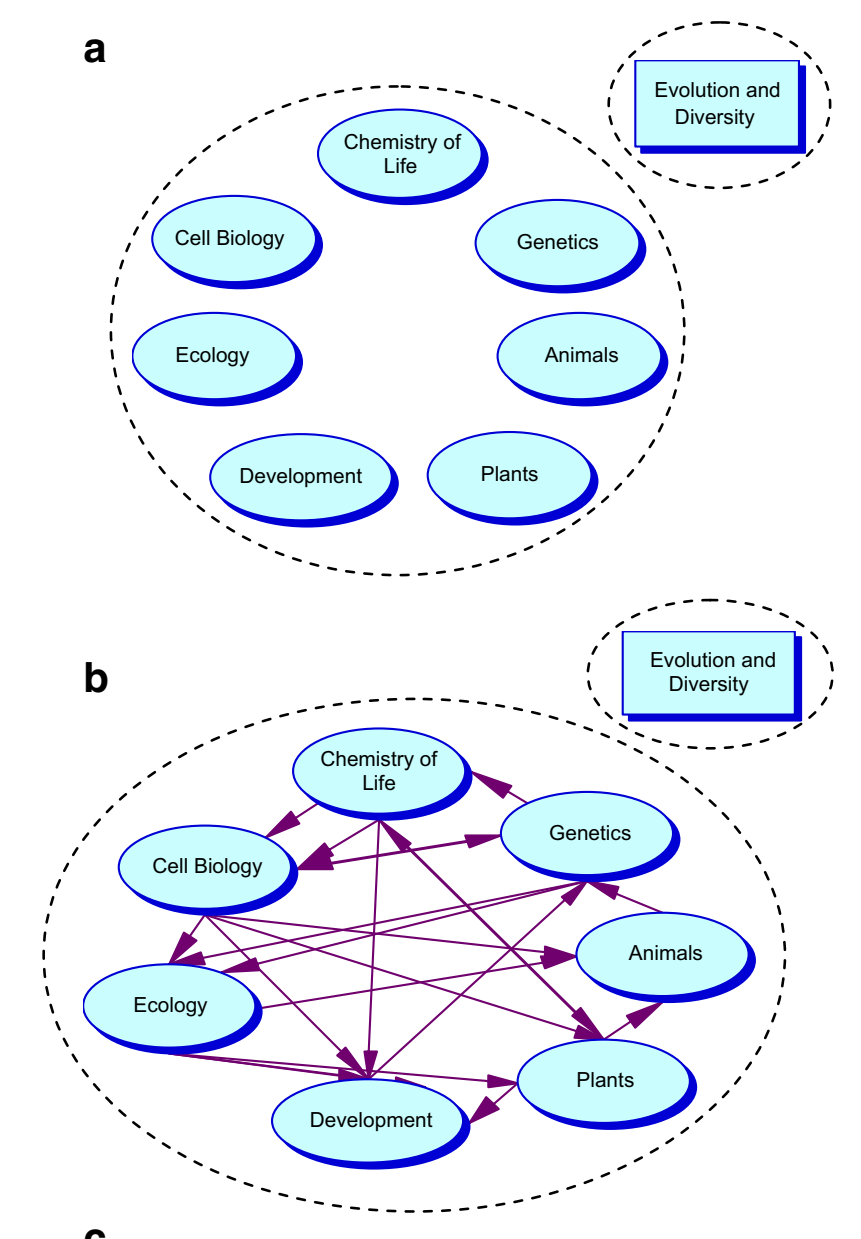

C

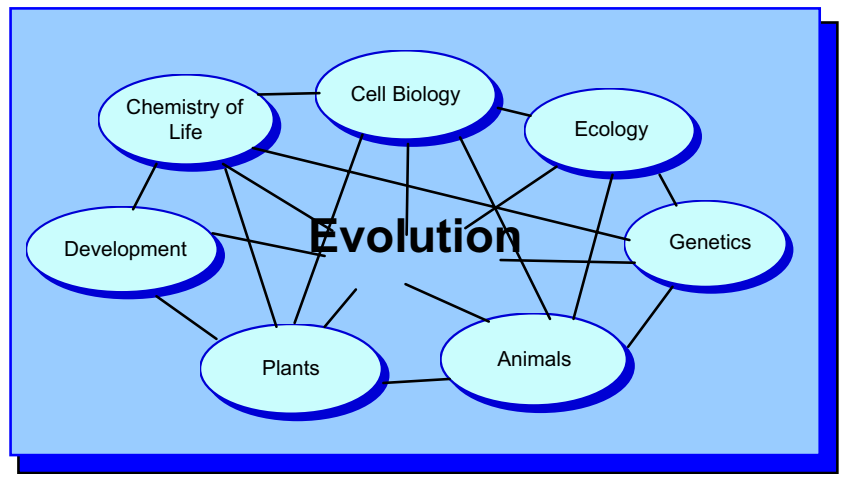

Fig. 1 Theoretical student cognitive models of biology and evolution. a Isolated content organization and understanding lacking knowledge integration and a unifying theoretical organizer. b Integrated content understanding with segregated knowledge of evolution and no theoretical organizer. c Evolution and diversity as the theoretical organizer, in which the domains of biology content are organized

Methodologically, we documented the corresponding chapters among books (e.g., "biology of plants" = "plant form and function") and analyzed all 3,690 pages of the three textbooks for evolutionary content using the indexes along with page checks. We were generous in our consideration of what counted as evolutionary content (e.g., phylogeny of a particular group, scientists associated with an evolutionary idea, etc.). Two different scorers had to agree on a term prior to its inclusion in the analysis. We scored the number of unique evolutionary concepts or terms per page (e.g., repeated use of "natural selection" on the same page only counted as one unit). We examined the frequency of evolutionary terms among chapters as well as the frequency standardized by the numbers of pages per chapter (Figs. 2 and 3, respectively).

Our content analyses of the three best-selling introductory biology textbooks for majors generally demonstrate the conceptual segregation of evolutionary information (Fig. 2). By far the vast majority of the evolutionary terms or concepts in each book were located in the sections about evolution and diversity, while remarkably few were used in the other sections of the books. Standardizing the data by number of pages per unit did not alter this pattern (Fig. 3). For example, of the total number of evolutionary terms employed in the texts, only $0.005 \%, 0.006 \%$, and $0.008 \%$ occurred in the plant form and function sections. Surprisingly, only $0.04 \%, 0.05 \%$, and $0.05 \%$ occurred in the genetics sections. Likewise, of the total evolutionary terms employed, only $0.004 \%, 0.006 \%$, and $0.07 \%$ occurred in the cell biology sections. Although terms are not the only way of measuring evolutionary content, and many of the texts include abundant references to evolution, they do illustrate a general-and longstanding - pattern that is concordant with evolutionary content segregation (Mayfield et al. 1960).

\section{Restructuring the Curriculum in Order to Restructure Mental Models}

We propose that it is empirically accurate and pedagogically sound to use evolution as the conceptual organizer in introductory biology courses (Hillis 2007). Two goals are central to our proposal for restructuring the curriculum and the textbooks that support them (1) desegregation of evolution as separate "units" or chapters and (2) active integration of evolutionary concepts at all levels and across all domains of introductory biology. By integrating evolution throughout the introductory biology sequence, educators would model for students how biologists employ evolution as a conceptual organizer for their own cognitive understanding of fields and ideas as diverse as genetics and ecology. Thus, when evolution serves as the conceptual organizer of the curriculum, it has the potential to (1) facilitate student linkages among the multitude of facts and ideas that students encounter in introductory biology, (2) provide a major narrative that weaves together major knowledge domains into a coherent story, and (3) enhance student understanding of why theories like evolution are so 
Fig. 2 Distribution of evolutionary terms in different content units of three best-selling biology textbooks for undergraduates in the United States. As is apparent, the three textbooks have similar content structures. We compared the frequency and distribution of evolutionary concepts within each unit and among textbooks. The unit names are similar but not identical to those in the texts. Textbook units are presented in chronological order (i.e., they begin with "Chemistry and Early Life" and end with "Ecology". Note that evolutionary terms and concepts are largely restricted to the evolution and diversity units of all three textbooks

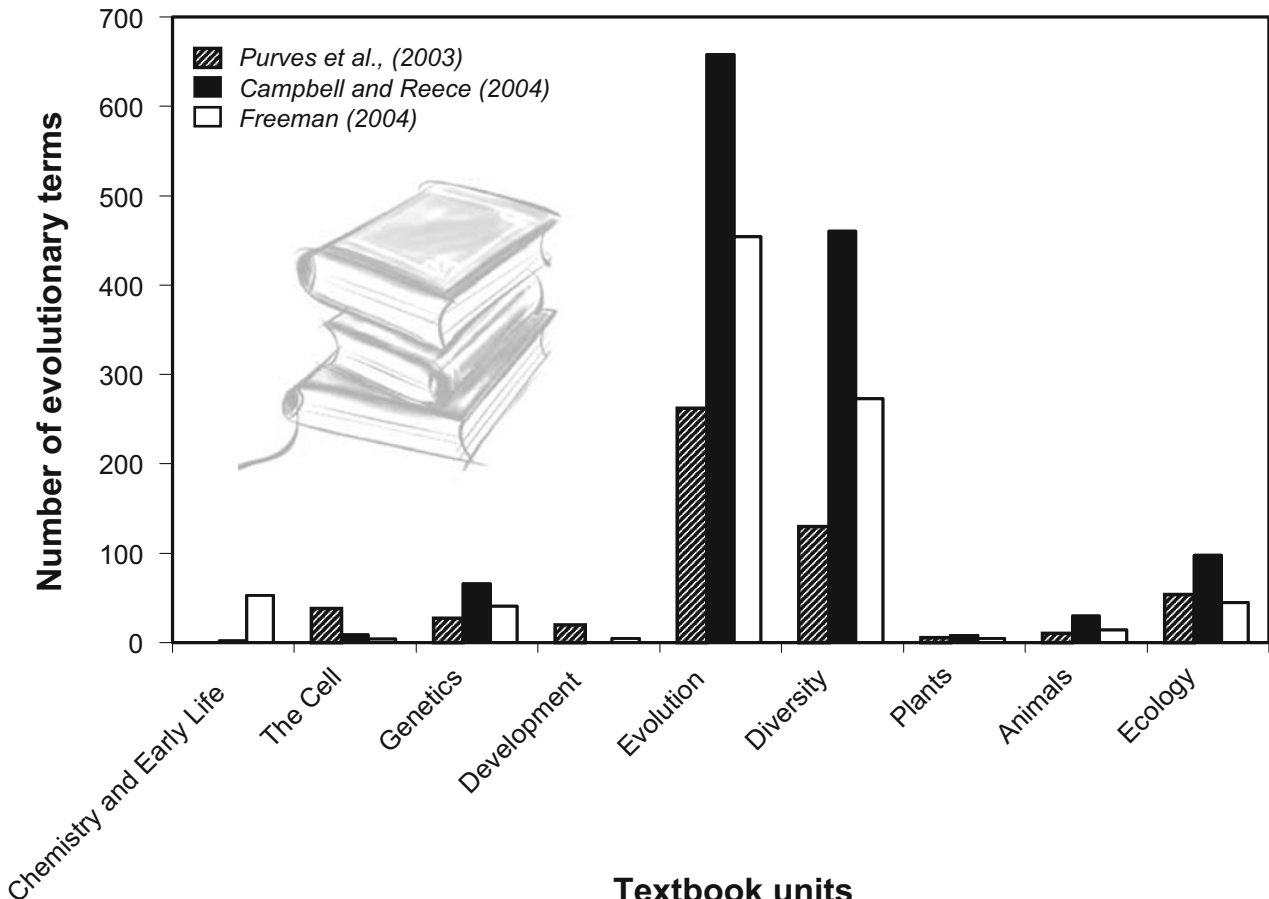

important to science: They integrate and make sense of diverse assemblages of facts, laws, inferences, and tested hypotheses (National Academy of Sciences 1996).

Studies have shown that the most effective science learning is accomplished when students are able to construct a solid framework to which they can subsequently add specific facts (National Research Council 2000). This is increasingly important as the biology student of today is expected to master a much greater amount of information per semester than their professors encountered at a similar stage in their careers. Unsurprisingly, numerous studies indicate that students are overwhelmed by the vast amount of information that they are expected to master (National Research Council 2003; Seymour and Hewitt 2000). Compounding this problem is that many students never develop the analytical skills required to generate the conceptual frameworks or mental models necessary for understanding the connections among related concepts,
Fig. 3 Distribution of evolutionary terms in textbook content units divided by the number of pages in each unit. Note that evolutionary terms and concepts are largely restricted to the evolution and diversity units of all three textbooks

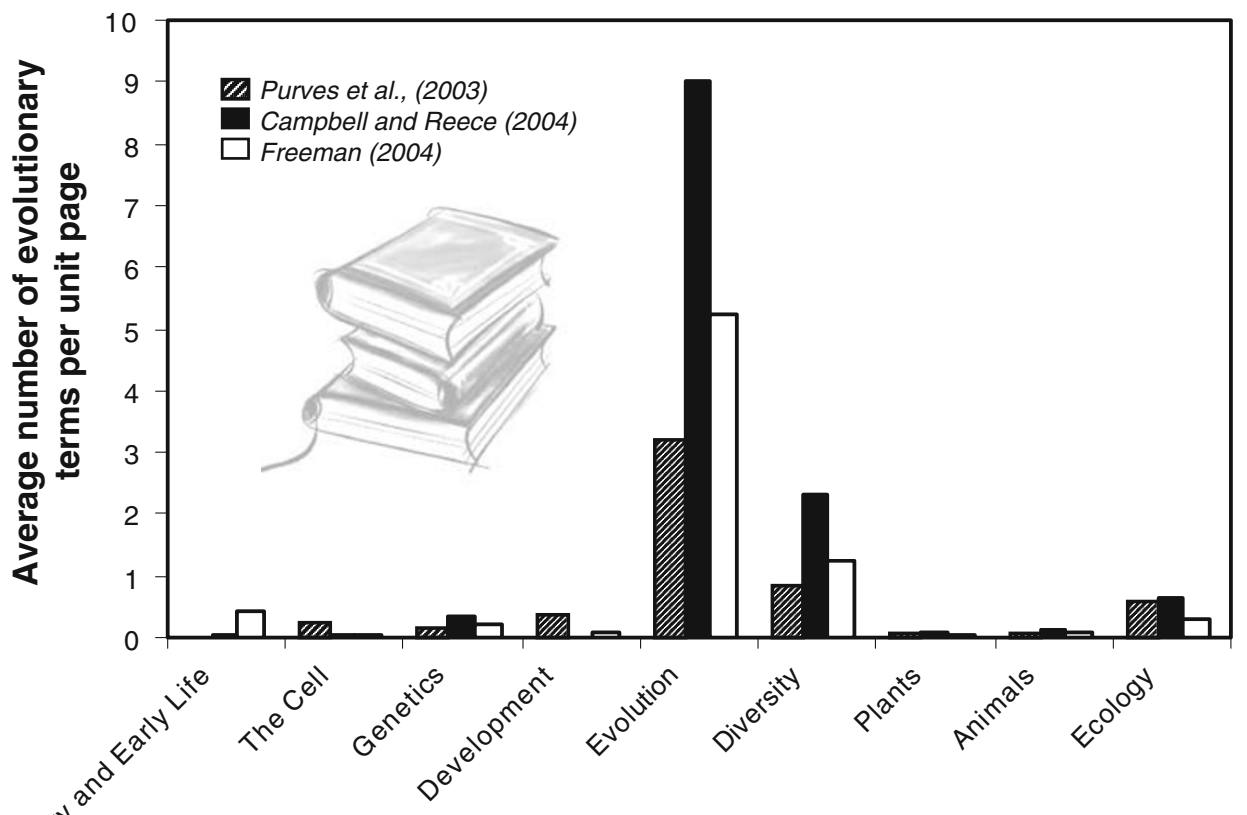

Textbook units 
mechanisms, and observations (National Research Council 2000, 2003).

Textbooks have exacerbated students' difficulties understanding biology's broader themes by overemphasizing technical terminology at the expense of providing meaningful narratives that allow students to weave key ideas into a coherent and sensible framework (Koppal and Caldwell 2004). Indeed, textbooks all too often fail to provide opportunities for students to draw connections among ideas that are necessary for building coherent understanding of a subject that typically characterizes "expertise" (Bloom 1956; Koppal and Caldwell 2004; National Research Council 2000). Like Mayfield et al. (1960), Huxley (1960), Dobzhansky (1973), and many others, we consider evolution to be this missing framework. Such a framework has great potential in helping students to conceptually organize, model, and understand biology.

The segregated presentation of information on evolution documented in our textbook study may explain why substantial numbers of biology students continue to perform well on exams, successfully complete a biology major, and/or become biology teachers while still retaining major misconceptions and antievolutionary attitudes (Brumby 1984; Bishop and Anderson 1990; Settlage 1994; Demastes-Southerland et al. 1995; Nehm and Schonfeld 2007). This format may facilitate college biology students' ignorance — or worse yet, rejection of — evolutionary ideas. Indeed, students fail to grasp that evolution is the unifying theme of biology while retaining a large and diverse array of isolated biological concepts perhaps because introductory courses reinforce their inaccurate mental models of biology (Fig. 1).

Our proposed integrative approach would also reinforce the idea that an understanding of evolution provides explanatory power and conceptual cohesion in areas of biology other than evolutionary biology itself. This approach has major implications because the rejection of an evolutionary worldview would then logically require the rejection of many aspects of cell biology, genetics, animal biology, plant biology, and ecology. When it becomes clear to students that evolutionary concepts underlie all levels of biological organization, the concept of rejecting evolution while accepting "the rest of" biology will naturally be recognized as absurd. While we acknowledge that many biologists and biology educators may in principle agree with our position, our concern is that biologists have not yet taken definitive action to build an integrative curriculum that will foster the development of accurate mental models in college undergraduates.

Changing the current situation requires fundamental changes in when, how, and where evolution is integrated into introductory biology. Toward this end, our group has started to develop new lesson plans that incorporate evolutionary concepts while simultaneously covering core content. We have begun to desegregate evolution in the introductory courses at our home institutions. We are evaluating the effectiveness of our approach in promoting accurate cognitive models of evolution and in reducing misconceptions and antievolutionary attitudes among our students (Nehm and Reilly 2007). We encourage other biologists to join our efforts.

Acknowledgments Our working group of biologists and biology educators was forged at the National Academy of Science's "National Academies Summer Institute on Undergraduate Education." We also thank Drs. Amy Chang and Nancy Dilulio for facilitating our group at the Summer Institute.

\section{References}

Anderson OR, Demetrius OJ. A flow-map method of representing cognitive structure based on respondents' narrative using science content. J Res Sci Teach 1993;30(8):953-69.

Anderson OR, Randle D, Covotsos T. The role of ideational networks in laboratory inquiry learning and knowledge of evolution among seventh grade students. Sci Educ 2001;85:410-25.

Bishop B, Anderson C. Student conceptions of natural selection and its role in evolution. J Res Sci Teach 1990;27:415-27.

Bloom B. Taxonomy of educational objectives, Handbook I: the cognitive domain. New York: David McKay; 1956.

Brumby M. Misconceptions about the concept of natural selection by medical biology students. Sci Educ 1984;68(4):493-503.

Campbell NA, Reece JB. Biology. 7th ed. Redwood City, CA: Benjamin Cummings; 2004.

Chinsamy A, Plaganyi E. Accepting evolution. Evolution 2007;62$1: 248-54$.

Clough EE, Wood-Robinson C. How secondary students interpret instances of biological adaptation. J Biol Educ 1985;19:125-30.

d'Apollonia S, Charles ES, Boyd GM. Acquisition of Complex Systemic Thinking: Mental Models of Evolution. Postsecondary Education: New Directions in Teaching and Learning. Special Issue of Educational Research and Evaluation; 2002.

Demastes-Southerland S, Good R, Peebles P. Students' conceptual ecologies and the process of conceptual change in evolution. Sci Educ 1995;79(6):637-66.

Dobzhansky T. Nothing in biology makes sense except in the light of evolution. Am Biol Teach 1973;35(3):125-9.

Freeman S. Biological science. 2nd ed. Englewood Cliffs, NJ: Prentice Hall; 2004.

Gentner D, Stevens A (Eds.). Mental Models. Mahwah, NJ: Lawrence Erlbaum; 1983.

Greene ED Jr. The logic of university students' misunderstanding of natural selection. J Res Sci Teach 1990;27:875-85.

Handelsman J, Ebert-May D, Beichner R, Bruns P, Chang A, DeHaan R, Gentile J, Lauffer S, Stewart J, Tilghman SM, Wood B. Scientific teaching. Science 2004;304:521-2.

Hellman RA. Evolution in American high school biology books from the late 19th century until the 1930s. Am Biol Teach 1965;27:778-80.

Hillis DM. Making evolution relevant and exciting to biology students. Evolution 2007;61(6):1261-4.

Huxley J. Evolution in the High School curriculum. School Rev 1960; IXVII: 167. 
Johnson-Laird PN. Mental models: towards a cognitive science of language, inference and consciousness. Cambridge, UK: Cambridge University Press; 1983.

Kennedy D. Breakthrough of the year. Science 2005;310:1869.

Koppal M, Caldwell A. Meeting the challenge of science literacy: project 2061 efforts to improve science education. Cell Biol Educ 2004;3:028-30.

Krippendorff K. Content analysis: An introduction to its methodology. 2nd ed. Thousand Oaks, CA: Sage; 2004.

Mayfield JC, Gowin DB, Boyajian R. Using modern knowledge to teach evolution in high school. Am Biol Teach 1960;22: 405-13.

Miller JD, Scott EC, Okamoto S. Public acceptance of evolution. Science 2006;313:765-6.

National Academy of Sciences. Evolution and the nature of science. Washington, D.C.: National Academies Press; 1996.

National Research Council. How people learn: brain, mind, experience, and school: expanded edition. 1st ed. Washington, D. C.: National Academies Press; 2000.

National Research Council. BIO 2010: transforming undergraduate education for future research biologists. Washington, D. C.: National Academies Press; 2003.
Nehm RH, Reilly L. Biology majors' knowledge and misconceptions of natural selection. Bioscience 2007;57(3):263-72.

Nehm RH, Schonfeld IS. Does increasing biology teacher knowledge of evolution and the nature of science lead to greater preference for the teaching of evolution in school? J Sci Teacher Educ 2007; 18:699-723.

Nehm RH, Schonfeld IS. Measuring knowledge of natural selection: a comparison of the CINS, and open response instrument, and oral interview. J Res Sci Teach 2008;45:1131-1160.

Purves WK, Sadava S, Heller C, Orians GH. Life: the science of biology. 7th ed. San Francisco, CA: Freeman; 2003.

Settlage J. Conceptions of natural selection: a snapshot of the sensemaking process. J Res Sci Teach 1994;31:449-57.

Seymour E, Hewitt NM. Talking about leaving: why undergraduates leave the sciences. Boulder, CO: Westview; 2000.

Skoog G. Topic of evolution in secondary school biology textbooks. Sci Educ 1979;63(5):621-40.

Swarts FA, Anderson OR, Swetz FJ. Evolution in secondary school biology textbooks of the PRC, the USA and the Latter Stages of the USSR. J Res Sci Teach 1994;31:475-505.

Woodin T. Personal communication, Summer Institute on Biology Education, Madison, WI; 2005 